\title{
Transparency, Inequity Aversion, and the Dynamics of Peer Pressure in Teams - Theory and Evidence
}

\author{
Alwine Mohnen, Kathrin Pokorny and Dirk Sliwka \\ University of Cologne*
}

February 2007

\begin{abstract}
We provide an explanation for peer pressure in teams based on inequity aversion. Analyzing a two-period model with two agents, we find that the effect of inequity aversion strongly depends on the information structure. When contributions are unobservable, agents act as if they were purely selfish. However, when contributions are made transparent at an interim stage, agents exert higher efforts in the first period and adjust their efforts according to the interim information in the second period. This form of peer pressure reduces free-riding and thus, more efficient outcomes are attained. The results are confirmed in a real effort experiment.
\end{abstract}

Key Words: Team, Transparency, Peer Pressure, Free-riding, Incentives, Inequity Aversion, Real Effort, Experiment

JEL Classification: D 23, M 12

*All Department of Personnel Economics and Human Resource Management at the University of Cologne, Herbert-Lewin-Strasse 2, 50931 Cologne, E-mail: alwine.mohnen@unikoeln.de, kathrin.pokorny@uni-koeln.de,dirk.sliwka@uni-koeln.de 


\section{Introduction}

In many real world contexts work results cannot be assigned to a particular person but merely to a group of people or a team. In that case any kind of performance dependent compensation is accompanied by the danger of free-riding and consequently inefficient effort levels. This problem has been discussed comprehensively in the theoretical and empirical literature in recent decades (e.g. Holmström (1982), Alchian and Demsetz (1972) and Newhouse (1973), or Prendergast (1999) for a survey).

However, it is sometimes claimed that peer pressure effects induce team members to work harder and to reduce free-riding. In this paper, we therefore provide a theoretical explanation for peer pressure effects based on agents' inequity aversion. In a second step, we then test the implications of our theory in a real effort experiment. One of the key objectives of our investigation is to study the impact of the informational structure on the development of peer pressure in teams.

We first consider a simple model in which two agents can contribute to a certain task and both are paid based on the total output of the team. Individual contributions depend on the effort exerted. We compare two settings: In the first setting, both agents can observe their respective contributions only after the end of the game. In the second setting each team member obtains intermediate information on the contribution of his team partner at an interim stage. We assume that both agents are inequity averse over their respective contributions, i.e. each dislikes contributing more or less to the final outcome than his team partner. We show that inequity aversion indeed affects the outcome provided that interim information on the respective contributions is given. The key mechanism is the following: When it has turned out that one of the agents has contributed more to a task than his team partner an inequitable situation arises. The team partner will have an incentive to reduce this inequity by exerting more effort in the following period. On the other hand, the agent who contributed more has an incentive to reduce 
his effort level. Hence, an interdependency arises between past outcomes and future contributions. But this has an important effect on the incentives to contribute early in the game as a higher contribution in the present raises the coworker's willingness to raise his effort in the future. Hence, this effect increases the marginal return of effort and leads to higher effort levels early in the game if the respective contributions are made transparent.

However, if individual contributions are not transparent and become known only at the end of the game, we show that inequity aversion has no impact on equilibrium effort levels as inequity averse agents act exactly like purely selfish agents would.

We test several hypotheses derived from the model in a real effort experiment. Each of the participants in the experiment was requested to perform a tedious counting task on a computer screen. Teams of two participants were remunerated with a linear piece rate based on the sum of correct answers of both participants. In the first condition participants learned the correct answers which their team partner attained at intermediate stages of the game. In the other condition they received that information only at the end of the experiment. The main hypotheses derived from the model are confirmed: Participants yield more correct answers when knowing that their team mates were informed about the intermediate outcomes. In addition, we find evidence that the difference between outcomes within the team in the previous period indeed has a strong impact on individual outcomes in subsequent periods. Interestingly we observe an asymmetry in the reaction: Whereas an agent who has contributed more than his colleague in the previous period reduces his effort strongly, having contributed less only leads to a weak increase in future effort.

Among the first introducing the idea of peer pressure in economic team models are Kandel and Lazear (1992). In their model, team members can choose certain actions that raise the cost of a reduction in individual productive effort for the other team members. However, the mechanism by which 
the costs of productive effort are increased is not studied endogenously in the model. Barron and Gjerde (1997) find that the existence of peer pressure can result in the optimality of lower powered incentives. Che and Yoo (2001) show that team incentives are more effective in an infinitely repeated game as team members can sanction past behavior of their colleagues. Knez and Simester (2001) find that the introduction of a company wide team incentive scheme at Continental airlines raised productivity significantly. They explain their result by claiming that mutual monitoring and peer pressure effects counterbalanced free-riding. Backes-Gellner et al. (2006) investigate a Kandel-Lazear type peer pressure model and find a concave relationship between team size and peer pressure which they confirm by empirically analyzing the effort exerted in groups of founders.

There is some previous experimental evidence on peer pressure in teams. Falk and Ichino (2006) show that subjects working at the same time in the same room work harder than subjects in a control treatment with one person working in a room all alone. In contrast to our study they remunerate their subjects with a fixed wage. Hence, increasing the other's incentives to contribute more can be no motive in their experiment. Sausgruber (2005) examines peer effects between teams rather than within teams. He finds that the average contribution of the other team in the previous period is positively correlated to the contribution of a person to the own team output in the current period. Empircial evidence for the importance of peer effects in firms have for instance been given by Ichino and Maggi (2000) or Knez and Simester (2001).

Our paper is of course also strongly related to the literature on social preferences. Fehr and Schmidt (1999) and Bolton and Ockenfels (2000) show that many experimental results can be explained when allowing for the possibility that some agents' utility decreases in the inequality of payoffs between agents. Recently a literature has emerged analyzing the incentive effects of several contractual forms when agents are inequity averse. Examples are for 
instance Biel (2004), Englmaier and Wambach (2002), Demougin and Fluet (2003), Grund and Sliwka (2005), or Itoh (2004). ${ }^{1}$ Most closely related to the theoretical part of our paper is Huck and Biel (2006) who give a rationale for leadership behavior in a game in which two agents are remunerated with a team incentive scheme. They show that output is higher when one of the agents (i.e. the leader) can act as a first mover as his effort level influences his follower when the latter is inequity averse. Masclet (2002) allows for punishment of shirking colleagues which is used in order to achieve equity.

Our analysis is also related to theoretical literature on dynamic voluntary contributions to public goods. Whereas for instance Admati (1991) or Fershtman and Nitzan (1991) have shown that dynamic interaction may actually aggravate the free-rider problem ${ }^{2}$ we find that even though the game is finite dynamic interaction may reduce free-riding when agents are inequity averse.

The remainder of the paper is organized as follows: In section 2 we present the model where the theoretical results regarding the non-transparent and transparent setting are developed in sections 2.1 and 2.2 respectively. The experimental design and hypotheses are described in 3.1 and 3.2. Section 3.3 deals with the empirical results. The last section concludes.

\section{The Model}

To examine the effects of transparency and inequity aversion on contributions to a team task, we consider the following set-up. Two risk neutral agents $i=1,2$ are working in team in two periods $t=1,2$. Each agent $i$ can contribute an effort $e_{i t}$ to the team task in period $t$. The agents' costs of effort in each period are represented by a quadratic cost function, $\frac{c}{2} e_{i t}^{2}$ with $c>0$. We assume that only the sum of efforts is verifiable such that individual piece

\footnotetext{
${ }^{1}$ For an overview see for instance Englmaier (2004).

${ }^{2}$ In contrast to these results, Marx and Matthews (2000) investigate a case in which efficient contribution levels can only be attained in a dynamic framework.
} 
rates are infeasible. Both agents receive a fixed wage as well as a team bonus paid at the end of period 2:

$$
w_{i}=\alpha+\beta \sum_{t=1}^{2}\left(e_{i t}+e_{j t}\right) \text { for } i=1,2 .
$$

Given this compensation scheme, the variable payment depends on the total team output, i.e. the sum of the contributions of both team members in both periods. Furthermore, we assume that both agents are inequity averse over their respective contributions. The utility function of an agent over both periods is given by

$$
u_{i}=w_{i}-\nu\left(\sum_{t=1}^{2}\left(e_{i t}-e_{j t}\right)\right)-\frac{c}{2} e_{i 1}^{2}-\frac{c}{2} e_{i 2}^{2}
$$

where

$$
\nu(\Delta)=\left\{\begin{array}{lll}
\frac{a}{2} \cdot \Delta^{2} & \text { if } & \Delta<0 \\
\frac{d}{2} \cdot \Delta^{2} & \text { if } & \Delta>0
\end{array}\right.
$$

with $d \geq a \geq 0$ where $\Delta=\sum_{t=1}^{2}\left(e_{i t}-e_{j t}\right)$ represents the total excess contribution of a player over his coworker's contribution across both periods. Thus, the utility of agent $i$ equals his remuneration less his effort costs in both periods and an expression reflecting the utility loss from inequity in contributions within the team. It is obvious that the agents do not suffer from inequity aversion when both contribute equally over both periods. But if the sum of contributions over both periods is not the same for both agents, inequity aversion leads to a loss in utility. Following Fehr and Schmidt (1999) we allow for the possibility that disadvantageous inequity brings about a larger utility loss than advantageous inequity. Note that this includes the possibility that $a=0$ such that we also investigate the case where the agent suffers only from inequity in contributions when it is to his disadvantage. Since it seems reasonable, that bigger differences lead to more than a proportional 
effect on the disutility of inequity than small differences in contributions, we model the utility loss of the differences in contributions as a convex function.

In our analysis we compare two cases. In the first case both agents obtain the information about their respective contribution to the team output at an interim stage after the first period. One possible interpretation would be that they closely work together in a transparent environment and therefore can observe their respective contributions after each period. Another explanation would be that feedback is given by a central manager after the first period who informs both agents about each others' contributions. We call this the transparent case. In the second case this intermediate information is not given but agents learn their respective contributions only after the second period. This case is labeled non-transparent case. Payoff functions are exactly the same in both cases. ${ }^{3}$

\subsection{Unobservable Contributions}

We first solve the game for the case where contributions are unobservable at the interim stage after period 1. Here, an agent knows in the first period, that his contributions will not be observed by the other agent before the second period ends. Hence, agents cannot react to their respective counterpart's contribution. Agent $i$ 's second period utility function is

$$
\alpha+\beta\left(e_{i 1}+e_{i 2}+e_{j 1}+e_{j 2}\right)-\nu\left(e_{i 1}+e_{i 2}-e_{j 1}-e_{j 2}\right)-\frac{c}{2} e_{i 2}^{2}
$$

The agent maximizes this expression given his own first period effort choice $e_{i 1}$ and his coworker's equilibrium strategies $\hat{e}_{j 1}$ and $\hat{e}_{j 2}$. The first order

\footnotetext{
${ }^{3}$ As we are interested in the impact of inequity aversion on effort provision, we focus on the agents' decisions rather than on the princpal's. Therefore we do not analyze the principal's optimal contracting. However, if agents are protected by limited liability, it can be shown that the principal will choose $\alpha=0$ and $\beta=1 / 2$.
} 
condition with respect to the second period effort level is

$$
\beta-\nu^{\prime}\left(e_{i 1}+e_{i 2}-\hat{e}_{j 1}-\hat{e}_{j 2}\right)-c e_{i 2}=0
$$

implicitly defining the agent's second period reaction function $e_{i 2}^{*}\left(e_{i 1}, \hat{e}_{j 1}, \hat{e}_{j 2}\right)$. When chosing the first period effort level, the agent will of course anticipate his own reaction in the second period. But by the envelope theorem, the first order condition for the first period effort choice corresponds to that in the second period. Hence, we must always have that $e_{i 1}=e_{i 2}=e_{i}$ and

$$
\begin{aligned}
& \beta-\nu^{\prime}\left(2 e_{i}-2 \hat{e}_{j}\right)-c e_{i}=0 \text { and } \\
& \beta-\nu^{\prime}\left(2 e_{j}-2 \hat{e}_{i}\right)-c e_{j}=0
\end{aligned}
$$

It is straightforward to see that a symmetric equilibrium exists in which

$$
e_{i t}=\frac{\beta}{c} \text { for } i=1,2 \text { and } t=1,2 \text {. }
$$

Moreover, this equilibrium is unique as is shown in the following result

Proposition 1 When agents cannot observe their respective contributions at the interim stage there is a unique subgame perfect equilibrium where effort levels are independent from the agent's degree of inequity aversion and are given by

$$
e_{i t}=\frac{\beta}{c} \text { for } i=1,2 \text { and } t=1,2
$$

Proof: See Appendix.

It is important to note that without transparency, the introduction of inequity aversion over contributions does not alter the equilibrium predictions compared to a case where agents are purely selfish. As the agents do not receive any information about their colleague's contribution to the team result 
after the first period, agents cannot adapt their effort choices contingent on their observation of that contribution.

\subsection{Observable Contributions}

In the transparency case, the contributions to the team output are observed by both agents at an interim stage. We examine how the observability of $e_{i 1}$ and $e_{j 1}$ influences the agents' decisions. Agents are symmetrically informed at the beginning of period 2. In period 2 agent $i$ maximizes his utility

$$
\max _{e_{i 2}} \alpha+\beta\left(e_{i 1}+e_{j 1}+e_{i 2}+\hat{e}_{j 2}\right)-\nu\left(e_{i 1}-e_{j 1}+e_{i 2}-\hat{e}_{j 2}\right)-\frac{c}{2} e_{i 2}^{2}
$$

where $\hat{e}_{j 2}$ is his coworker's equilibrium strategy in the second period. Suppose without loss of generality that agent $i$ contributes weakly more than his coworker in equilibrium over both periods, i.e. $e_{i 1}+e_{i 2} \geq e_{j 1}+e_{j 2}$. Then the first order conditions of the agents's second period objective functions are given by

$$
\begin{aligned}
\beta-d\left(e_{i 1}-e_{j 1}+e_{i 2}-\hat{e}_{j 2}\right)-c e_{i 2} & =0 \text { and } \\
\beta-a\left(-\left[e_{i 1}-e_{j 1}+\hat{e}_{i 2}-e_{j 2}\right]\right)-c e_{j 2} & =0
\end{aligned}
$$

from where we obtain the following reaction functions

$$
\begin{aligned}
e_{i 2} & =\frac{\beta-d\left(e_{i 1}-e_{j 1}-\hat{e}_{j 2}\right)}{(c+d)}, \\
e_{j 2} & =\frac{\beta+a\left(e_{i 1}-e_{j 1}+\hat{e}_{i 2}\right)}{(c+a)} .
\end{aligned}
$$

Note that $e_{i 2}$ is increasing in $\hat{e}_{j 2}$ and $e_{j 1}$ and decreasing in $e_{i 1}$. Besides the monetary motive, the agent's effort choice is guided by his objective to minimize the expected disutility from inequity. An agent works the harder, the more effort is exerted by his colleague in equilibrium in the current period and the higher the contribution of his colleague in the previous period has 
been. He works the less, the more he himself has contributed in the previous period.

When solving this system of equations we obtain the following result:

Proposition 2 When contributions are transparent at the interim stage and agent $i$ contributed more in the first period, the equilibrium effort levels in period 2 are

$$
\begin{aligned}
e_{i 2} & =\frac{\beta}{c}-\frac{d}{c+a+d}\left(e_{i 1}-e_{j 1}\right) \text { and } \\
e_{j 2} & =\frac{\beta}{c}+\frac{a}{c+a+d}\left(e_{i 1}-e_{j 1}\right) .
\end{aligned}
$$

An agent who contributed less in the first period will now contribute more and the one who contributed more will make a smaller contribution than his coworker. If $d>$ a the total output in the second period is strictly decreasing in the difference in first period effort levels $e_{i 1}-e_{j 1}$.

Proof: See Appendix.

Now, the efforts exerted in the second period depend upon the actual output in the first period. When the first period contributions of both agents differ, the agent with the higher contribution exerts a lower and the one with the lower contribution chooses a higher second period effort level than in the case without transparency (or the case where all agents are purely selfish). An agent whose first contribution has been high, feels less obliged to exert higher effort levels in the second period. On the other hand, an agent whose first period contribution has been low, strives to make up for the difference by exerting a higher effort level in the second period. However, when disadvantageous inequity has a stronger impact on an agent's utility than advantageous inequity, i.e. $d>a$, the latter effect is weaker than the former. In this case, the sum of both effort levels $e_{i 2}+e_{j 2}$ is strictly decreasing in the difference in first period effort levels. 
It is interesting to note that the difference in total contributions is

$$
e_{i 1}-e_{j 1}+e_{i 2}-e_{j 2}=\frac{c}{c+a+d}\left(e_{i 1}-e_{j 1}\right)
$$

Hence, when one agent has contributed more in the first period, the same agent will in the end make the larger total contribution. When first period contributions are unequal, this inequity will be reduced but it will not disappear entirely.

In period 1 agent $i$ maximizes his utility

$$
\max _{e_{i 1}} \alpha+\beta \sum_{t=1}^{2}\left(e_{i t}+\hat{e}_{j t}\right)-\nu\left(\sum_{t=1}^{2}\left(e_{i t}-\hat{e}_{j t}\right)\right)-\frac{c}{2} e_{i 1}^{2}-\frac{c}{2} e_{i 2}^{2} .
$$

now taking the effect of $e_{i 1}$ on the equilibrium strategies of both agents in period 2 into account. Note that the functional form of an agent $i$ 's objective function in the first period depends on whether $e_{i 1} \geq \hat{e}_{j 1}$. Due to the asymmetry in the utility loss from inequity, the second period reaction on differences in first period contributions will depend on whether the agent has contributed more or less than his coworker. Using the second period equilibrium strategies (5) and (6) the first period objective function of agent $i$ becomes

$$
\begin{aligned}
& \alpha+\beta\left(e_{i 1}+\hat{e}_{j 1}\right)-\frac{c}{2} e_{i 1}^{2}+\beta \frac{2 \beta}{c} \\
& +\left\{\begin{array}{l}
-\beta \frac{(d-a)\left(e_{i 1}-\hat{e}_{j 1}\right)}{c+a+d}-\frac{d}{2}\left(\frac{c\left(e_{i 1}-\hat{e}_{j 1}\right)}{c+a+d}\right)^{2}-\frac{c}{2}\left(\frac{\beta}{c}-\frac{d\left(e_{i 1}-\hat{e}_{j 1}\right)}{c+a+d}\right)^{2} \text { if } e_{i 1} \geq \hat{e}_{j 1} \\
+\beta \frac{(d-a)\left(e_{i 1}-\hat{e}_{j 1}\right)}{c+a+d}-\frac{a}{2}\left(\frac{c\left(e_{i 1}-\hat{e}_{j 1}\right)}{c+a+d}\right)^{2}-\frac{c}{2}\left(\frac{\beta}{c}-\frac{a\left(e_{i 1}-\hat{e}_{j 1}\right)}{c+a+d}\right)^{2} \text { if } e_{i 1}<\hat{e}_{j 1}
\end{array} .\right.
\end{aligned}
$$

The first derivative with respect to $e_{i 1}$ can be simplified to

$$
\left\{\begin{array}{ll}
\beta\left(\frac{c+2 a+d}{c+a+d}\right)-\frac{(c+d) d c}{(c+a+d)^{2}}\left(e_{i 1}-\hat{e}_{j 1}\right)-c e_{i 1} \quad \text { if } & e_{i} \geq \hat{e}_{j 1} \\
\beta\left(\frac{c+2 d+a}{c+a+d}\right)-\frac{(c+a) a c}{(c+a+d)^{2}}\left(e_{i 1}-\hat{e}_{j 1}\right)-c e_{i 1} & \text { if } \quad e_{i}<\hat{e}_{j 1}
\end{array} .\right.
$$


The second derivative of the objective function is always negative, i.e. the function is strictly concave. Hence, a necessary and sufficient condition for the existence of a symmetric equilibrium in which both agents choose the same effort level $e_{1}^{*}$ in the first period is that the right derivative is weakly negative and the left derivative weakly positive at $e_{i 1}=\hat{e}_{j 1}=e_{1}^{*}$ which is the case whenever

$$
\frac{\beta}{c}\left(\frac{c+2 a+d}{c+a+d}\right) \leq e_{1}^{*} \leq \frac{\beta}{c}\left(\frac{c+2 d+a}{c+a+d}\right) .
$$

As this set is non-empty there are multiple symmetric equilibria in the first period. Furthermore, there are no asymmetric equilibria as shown in the following result:

Proposition 3 When contributions are transparent, there is a continuum of pure strategy equilibria in the first period, which all are symmetric. The equilibrium effort levels exerted are characterized by

$$
\begin{aligned}
\frac{\beta}{c}\left(\frac{c+2 a+d}{c+a+d}\right) & \leq e_{i 1}^{*}=e_{j 1}^{*} \leq \frac{\beta}{c}\left(\frac{c+a+2 d}{c+a+d}\right) \text { and } \\
e_{i 2}^{*} & =e_{j 2}^{*}=\frac{\beta}{c} .
\end{aligned}
$$

If $a>0$, first period effort and utility levels are always higher than in the non-transparent setting.

Proof: See Appendix.

Hence, inequity aversion helps to reduce the free rider problem even in a finitely repeated game. In the first period, both work harder in the transparency case even in the worst possible equilibrium as long as agents dislike advantageous inequity at least to some extent. By exerting higher effort levels in the first period an agent can increase his team partner's costs to free-ride in the second period which are due to a utility loss caused by inequity aversion. 
But this mechanism only works when contributions are made transparent at the interim stage. Hence, the principal will always prefer a situation in which the agents observe each others' contributions providing him with higher efforts in the first period and thus higher total efforts. Moreover, also the agents benefit from the reduction of the free-riding problem as their utility is larger when contributions are transparent.

It is interesting to consider the special case where agents suffer only a utility loss when inequity is to their disadvantage but do not feel bad when they have contributed less, i.e. $a=0$ in our model. Note that in this case an agent cannot induce his coworker to work harder by exerting a higher effort level. Hence, the effort levels exerted by purely selfish agents (i.e. $e_{i 1}=e_{j 1}=\frac{\beta}{c}$ ) are part of a feasible equilibrium. But other equilibria exists as well as the set of effort levels sustainable in equilibrium is given by $\left[\frac{\beta}{c}, \frac{\beta}{c} \frac{c+2 d}{c+d}\right]$. Thus, higher effort levels can be attained, and moreover, these other feasible equilibria pareto-dominate the selfish equilibrium. To understand the reason for the existence of these pareto-superior equilibria consider the following: Suppose that an agent believes that his coworker exerts an effort level $\hat{e}_{j 1}$ stricly larger than $\frac{\beta}{c}$. When the agent matches $\hat{e}_{j 1}$, both will choose an effort level of $\frac{\beta}{c}$ in the second period. However, a deviation to a lower effort in the first period will lead his coworker to reduce his second period effort below the selfishly optimal level of $\frac{\beta}{c}$ as the coworker wants to reduce the disadvantageous inequity between contributions. It is therefore better to match $\hat{e}_{j 1}$ as long as it is not too large. Hence, the avoidance of disadvantageous inequity generates a credible threat that low team contributions will be punished in the future and this may well help to reduce the free-rider problem.

Hence, inequity aversion yields an explanation for peer pressure effects in teams. This explanations rests on two mechanisms: On the one hand, the marginal return of effort is higher when agents are inequity averse as higher efforts induce coworkers to exert higher efforts in the future. But in addition, agents will have an incentive to match effort levels exerted by their coworkers 
as a deviation will be credibly sanctioned by a reduction of efforts below the selfishly optimal level. Hence, equilibria can be sustained in which the agents choose higher effort levels than those exerted by purely selfish agents.

\section{Experimental Evidence}

\subsection{The Experimental Design and Procedures}

We then conducted a real effort experiment to study the impact of transparency on team contributions. Subjects were randomly assigned to a team consisting of two persons each. The team partners were never exchanged, thus each participant kept his counterpart for the entire duration of the experiment. Interaction was anonymous through the experimental software such that the subjects did not know each other's identity. Altogether 7 periods were played each of which lasted 8 minutes. In all periods the participants were offered to work on the following task: The participants were requested to determine the correct number of sevens in blocks of random numbers. ${ }^{4}$ Periods 1 and 7 (i.e. the first and the last period) were different from the other periods, in these periods subjects were paid according to their individual performance in the counting task. For each correct answer they received a piece rate of $0.14 €$ which was directly transferred to their individual account. We will call these periods the individual periods in the following. The individual periods at the very beginning and at the end of the experiment were introduced to provide individual ability measures for this specific task for each participant. In addition the use of these periods allows us to study how learning or fatigue influenced the results. ${ }^{5}$

However, in all other periods (i.e. periods 2 to 6 ) the participants had the choice between two options at each point in time: First, they could again

\footnotetext{
${ }^{4} \mathrm{An}$ example of the task is available from the authors on request.

${ }^{5}$ For instance this might be worth while if we want to distinguish between fatigue and an endgame effect when performance happens to decrease in the last team period.
} 
work on counting the correct number of sevens in blocks of random numbers. In that case $0.14 €$ were transferred to the team account for each correct answer. After each period the amount of the team account was equally divided between the two team members and we therefore call these periods the team periods. But, alternatively, the subjects could push a time-out button at any time during the team periods which caused the screen to be blocked for 25 seconds. During this time they were not able to continue with the counting task but were paid $0.10 €$ to their individual account. We introduced the time-out button to make sure that subjects had significant opportunity costs of working on the counting task.

Whenever an answer in the calculation task was incorrect $0.01 €$ were subtracted from the individual account irrespective of the type of period (individual or team period). After each team period every subject was informed about

- the number of blocks he had worked on in the previous period

- the number of correct answers he had given in the previous period

- the number of times he pushed the time-out button in the previous period.

In order to check for the impact of the team mate's performance on the individual effort, we introduced two conditions. Subjects in the nontransparent condition merely received the information described above. In the transparent condition however participants were additionally informed about the number of correct answers provided by their respective counterpart.

Altogether 208 students of various faculties participated in the experiment. We recruited all subjects using an online recruitment system by Greiner (2003). We conducted 7 sessions in May 2006 at the Cologne Laboratory for Economic Research, University of Cologne and used the experimental 
software z-tree by Fischbacher (1999) for programming the experiment. Each subject was seated in a separate cabin with a computer terminal. The participants were not given any oral instructions, instead all informations were described on a sheet of paper laid out in each cabin. ${ }^{6}$ Additionally, the structure of the payoff function and other important features of the experimental design were repeated on the computer screen before each period started. At the end of the experiment all subjects were informed about the sum of their earnings in the individual periods and the team periods. Additionally, they were all paid a fixed show up fee of $2.50 €$. On average the subjects earned approximately $16 €$. The whole procedure took about 90 minutes.

\section{$3.2 \quad$ Hypotheses}

From the theoretical model developed in section 2 we derive three main hypotheses on the subjects' behavior. Proposition 2 indicates that subjects will adapt their effort in counting according to the interim information.

Hypothesis 1 In the transparency condition the subjects having made the higher team contribution in the previous period compared to the team mate will decrease their effort in the next period and vice versa.

Hypothesis 1 captures the effect that the agents dislike differences in contributions between team members. Hence, the one who has taken an early lead will reduce and the one who has fallen behind will feel obliged to raise his effort in order to counterbalance the outcome difference from the previous period.

Moreover, we have seen that in Proposition 3 for each $a>0$ transparency leads to higher first period effort choices. Therefore we hypothesize:

Hypothesis $\mathbf{2 a}$ In periods 2 to 5 outcomes are higher in the transparent than in the non-transparent setting.

\footnotetext{
${ }^{6}$ For the printed instructions see appendix.
} 
This hypothesis illustrates the agents' incentives to exert higher efforts to increase the team mate's cost of free-riding. This effect is likely to persist as long as there is at least one subsequent period. However, in the last period the outcome cannot influence the team mate's future behavior.

Hypothesis $\mathbf{2} \mathbf{b}$ In the last team period (period 6), efforts decline in the transparent condition and the difference between the outcomes in the two informational settings diminishes.

The aggregate results should therefore be equal for both settings in the last period.

\subsection{Results}

Let us first consider the subjects' effort adjustment depending on the relation of their own contribution to the team output compared to the counterpart's contribution. We approximate the participants' effort by the number of correct answers given (score) to investigate this relation. ${ }^{7}$ Still we have two further effort measures to check the robustness of the score results which are on the one hand the number of blocks the subject has worked on irrespective of the correctness of the result (blocks), and on the other hand the number of time outs the subject has taken (time outs). ${ }^{8}$

As effort adjustment according to the counterpart's contribution is not possible for the non-transparent condition we restrict the analysis of the effort adjustment to the data from the transparent condition. Let us first examine how a subject's change in scored points from one period to the next is influenced by the score difference within his team in the previous period. According to Hypothesis 1 we expect that those subjects having taken a lead over their team mate in the previous period will reduce their effort in the

\footnotetext{
${ }^{7}$ The expressions in parentheses are the variable labels used in the following analysis.

${ }^{8}$ Note that the relation between the measures score and blocks and effort can be assumed to be positive and that it should be negative for time outs.
} 
next, while those team members who have fallen behind will increase their effort. To analyze this, we measure the difference in scores within the team (team difference). For the subject who produced the higher score, the team difference variable has a positive sign and for the subject with the lower performance the team difference variable has a negative sign. Second, we approximate the participants' effort adjustment by the score change variable. The score change is defined by the difference between a subject's score in the current period less the same subject's score in the previous period. Thus, if a subject increased the score between two consecutive periods, the score change is positive while it is negative if the subject decreased the score. We predict a negative relationship between the team difference in the previous periods and the score change from the previous to the subsequent periods. Figure 1 shows this relationship for periods $3,4,5$, and 6 .

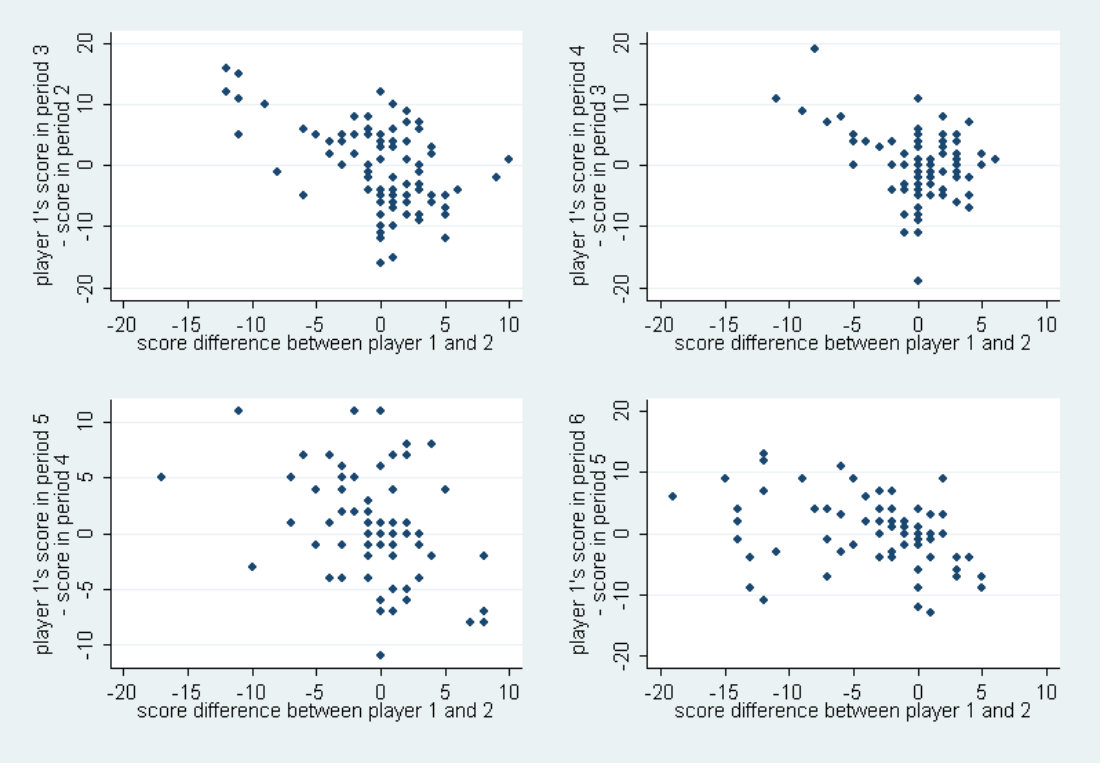

Figure 1: Relation between team differences in $t-1$ and score adaptions in $t$

According to Figure 1, indeed, this negative relationship seems to exist. We test the results illustrated in the previous figure by applying a fixed 


\begin{tabular}{|c|c|c|c|}
\hline & $\begin{array}{c}\text { (1) } \\
\text { Score } \\
\text { change }\end{array}$ & $\begin{array}{c}(2) \\
\text { Blocks } \\
\text { change }\end{array}$ & $\begin{array}{c}(3) \\
\text { Time outs } \\
\text { change }\end{array}$ \\
\hline $\begin{array}{l}\text { Team Difference } \\
\text { in t-1 }\end{array}$ & $\begin{array}{c}-0.563^{* * *} \\
(0.054)\end{array}$ & $\begin{array}{c}-0.649^{* * *} \\
(0.073)\end{array}$ & $\begin{array}{c}0.539^{* * *} \\
(0.061)\end{array}$ \\
\hline Constant & $\begin{array}{c}-2.739^{* * *} \\
(0.39)\end{array}$ & $\begin{array}{c}-2.852^{* * *} \\
(0.53)\end{array}$ & $\begin{array}{c}3.068^{* * *} \\
(0.44)\end{array}$ \\
\hline Observations & 352 & 352 & 352 \\
\hline Number of subjects & 88 & 88 & 88 \\
\hline$R^{2}$ & 0.36 & 0.27 & 0.27 \\
\hline
\end{tabular}

Table 1: The impact of differences in contributions in the previous period

effects estimation which we restrict to periods 2 to $6 .^{9}$ The models in Table 1 examine the influence of the team difference on the change between periods in the three performance measures (score, blocks and time out). ${ }^{10}$ Considering model (1) we observe a highly significantly negative influence of the team difference on the score change. From that we may conclude that the more a subject's score exceeded the counterpart's score in the past period, the more the subject decreased his effort in the subsequent period. In turn the participants raised the score if confronted with a negative team difference.

The models for block change (2) and time out change (3) confirm this conclusion. Model (2) demonstrates that higher performance differences within the team do not only lead to a decrease in the number of correct answers between the current and the previous period but also to a decrease in the number of blocks worked on. In turn a higher performance difference in the

\footnotetext{
${ }^{9}$ Period 2 is used only as a baseline for the changes in period 3.

${ }^{10}$ The variables block change and time out change are defined (analogously to score change) as the differences between the values of the respective measure in the current period less the value of the measure in the previous period.
} 
team causes the usage of the time-out button to rise (see model (3)). It seems that the subject with the higher outcome feels free to take time outs more often to counterbalance the team difference. This is well in line with our theoretical results.

In the estimation described above we only used the latest within team score difference (i.e. from the last precedent period). To check the robustness we ran a similar fixed effects estimation but used the mean aggregate team difference of all past periods to explain the effort adjustments. The results are presented in Table A1 in the Appendix. All three models confirm the results from Table 1. As another robustness check we used the information generated in the individual periods as a proxy for subject specific abilities in a random effects regression. The findings which are illustrated in Table A2 in the Appendix show that including individual abilites does not alter the results either.

So far, we assumed in the empirical investigation that the sign of difference in previous contributions has no impact on the strength of the effort adjustment. However, the theoretical model allowed for the possibility that agents suffer to a stronger extent from disadvantageous than from advantageous inequity leading. To investigate this, we ran further estimations presented in Table 2 to analyze possible differences in the strength of the effort changes between the team member who contributed more in the previous period (higher performer) and the one with the lower contribution (lower performer). The higher performer variable is defined as the maximum of zero and the difference between the subject's and its counterpart's score. Analogously the lower performer variable is the maximum of zero and the difference between the counterpart's and the respective subject's score.

Regarding models (1) and (2) we observe a significantly negative reaction of the higher performer. This is very intuitive because the more a person's score exceeded that of a coworker in the past period, the more he reduces the current effort in order to attain a stronger equality in contributions. This 


\begin{tabular}{lccc}
\hline \hline & $\begin{array}{c}(1) \\
\text { Score } \\
\text { change }\end{array}$ & $\begin{array}{c}(2) \\
\text { Blocks } \\
\text { change }\end{array}$ & $\begin{array}{c}(3) \\
\text { Time outs } \\
\text { change }\end{array}$ \\
\hline Higher Performer & $-0.987^{* * *}$ & $-1.092^{* * *}$ & $0.932^{* * *}$ \\
in t-1 & $(0.081)$ & $(0.11)$ & $(0.093)$ \\
Lower Performer & $0.139^{*}$ & $0.207^{*}$ & -0.145 \\
in t-1 & $(0.081)$ & $(0.11)$ & $(0.093)$ \\
Constant & $2.338^{* * *}$ & 0.398 & 0.518 \\
& $(0.51)$ & $(0.72)$ & $(0.59)$ \\
\hline Observations & 352 & 352 & 352 \\
Number of subjects & 88 & 88 & 88 \\
$R^{2}$ & 0.45 & 0.33 & 0.34 \\
\hline \hline Standard errors in parentheses, ${ }^{* * *} \mathrm{p}<0.01, * * \mathrm{p}<0.05, * \mathrm{p}<0.1$ \\
Fixed effects estimation (period dummies included)
\end{tabular}

Table 2: The impact of advantageous and disadvantageous inequity in contributions

effect occurs for the score change and the blocks change as well as for the time outs.

For the lower performer variable all coefficients show the opposite sign, hence, lower performers indeed increase their effort levels. But the effect sizes and levels of significance are less pronounced. This is particularly interesting and well in line with our model. In the language of the model, it confirms that actually $d>a$ expressing that differences in contributions are not equally detrimental for advantageous and disadvantageous inequality. In contrast, the subjects' behavior implies that they seem to suffer to a stronger extent from having contributed much more than the coworker than from having a 'bad conscience' when having contributed less. Hence, all the results are well in line with Hypothesis 1 and the predictions of the theoretical model.

Although we have seen that subjects adapted their effort according to their team mates' scores, it is so far not clear whether this behavior leads 


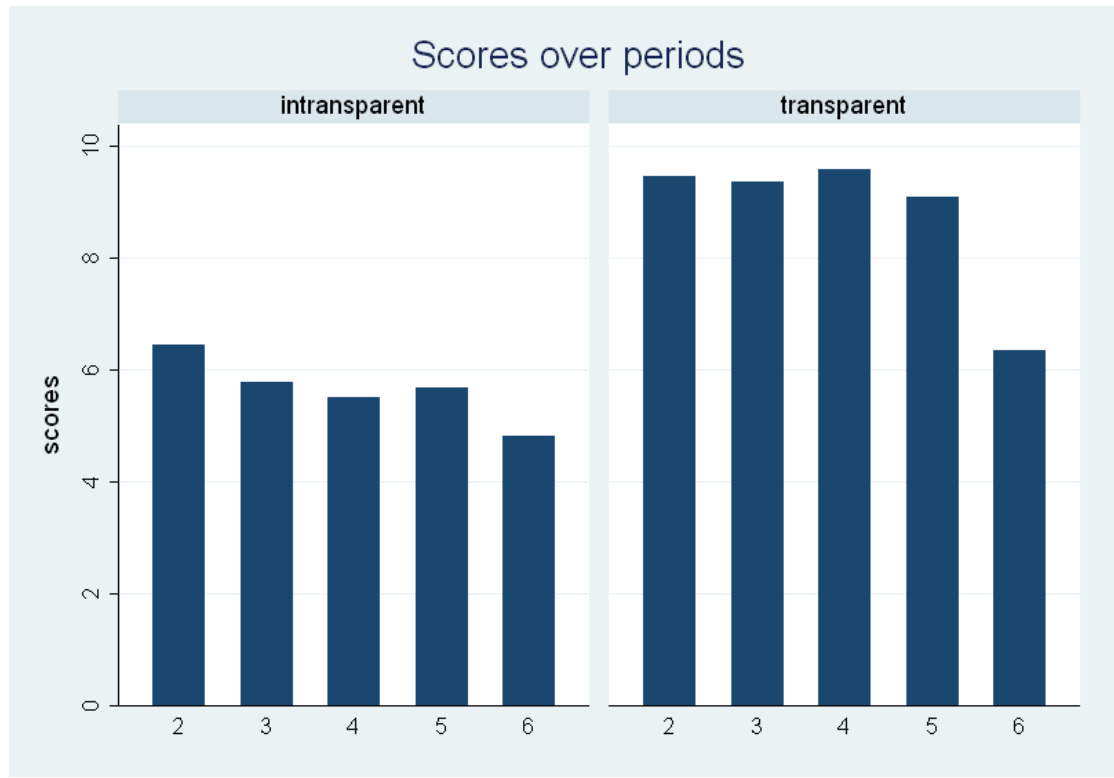

Figure 2: Scores over periods by condition

to a net increase in the total performance. Therefore we compare the scores between the transparent and the non-transparent condition. In Figure 2 the point scorings over the team periods 2 to 6 are displayed. The figure indicates that subjects in the non-transparent condition indeed attain lower scores than those in the transparent condition. In addition there seems to be a considerable endgame effect as scores drop in the transparent condition in the last period. In the non-transparent condition the effect seems to occur as well but appears to be less pronounced. ${ }^{11}$ We analyze each period separately with a non-parametric Mann-Whitney-U-test to check whether the differences between conditions are significant. Comparing the mean score per team for each period we find in each of the periods 2 to 5 scores are significantly higher

\footnotetext{
${ }^{11}$ The difference between period 5 and 6 is highly significant for the transparent condition if we use the Wilcoxon matched pairs signed rank test for dependent samples (absolute z-value 4.720).
} 
in the transparent than in the non-transparent setting. ${ }^{12}$ This confirms our Hypothesis 2a. Hence, we can conclude that indeed transparency in team production leads to higher effort levels and reduced free-riding behavior.

It is interesting to note that we do not find significant differences between the conditions in period 6 , the last period with team interaction. This seems to be an endgame effect indicating that subjects indeed have contributed more in the transparent case because they rationally anticipated the positive impact of a higher effort on the team mate's future effort. Of course, in the last period this motive became irrelevant as there was no subsequent period.

Finally, one might also argue that fatigue caused the scores to decline in period 6. However, using the Wilcoxon matched pairs signed rank test for dependent samples, we find a highly significant increase in scores in period 7 which is an individual period (absolute z-value 5.774). This indicates that subjects might not have suffered from fatigue but indeed did not have incentives to stick to the high effort level in period 6 providing evidence for Hypothesis 2b.

\section{Discussion}

In this paper we have theoretically and experimentally analyzed the impact of inequity aversion on effort incentives when agents work in a team in order to provide a possible explanation for peer pressure effects. We have shown that not only in theory but also in the experiment the effect strongly depends on the informational setting in which the task is solved.

The theoretical results suggest that when there no information about the team mates' contributions at an interim stage, the agents' inequity aversion does not influence the effort choices. Hence, the players always act identically to purely selfish ones. However, if the team mate's contribution can be observed at an interim stage, the agents deviate from the purely selfish choice.

\footnotetext{
${ }^{12}$ See table A3 in the Appendix for the z-values.
} 
Inequity aversion leads the agents to adjust their effort levels in the second period such that the agent having worked less increases and the other one who contributed more decreases his effort level.

The subjects in our experiment indeed adapted their effort according to the interim information they received about their counterparts' contribution such that they counterbalanced contributions to increase equity. But they did not adjust in a symmetric way. According to the observed behavioral pattern subjects who exerted higher effort levels than their team partner and therefore were in a disadvantageous position strongly decreased their effort in the subsequent period. Those participants having an advantage as they had been lazier felt the need to reduce inequity by increasing their efforts. But did so to a weaker extent leading to a less pronounced absolute adjustment for the lower performers. Hence, the notion of an asymmetric effect of advantageous and disadvantageous inequity illustrated in the model seems to be well reflected in the experiment.

A key conclusion from the theoretical model as well as from the experiment is that agents work harder in the early in the game to increase the team mate's costs of free-riding and therefore his future effort adjustment when contributions are transparent. Hence, the total sum of efforts is greater in the transparent than in the non-transparent case. Thus, we may conclude that transparency leads to more efficient outcomes and should therefore be preferred from a social welfare point of view. Hence, the main practical implication is that transparent work environments might be desirable in firms when employees work in groups. If workers adhere to a social norm evoking feelings of guilt or anger respectively for differences in team contributions, transparency might enhance the chance to develop beneficial mutual monitoring and in turn yield an effective reduction in free-riding. 


\section{Appendix}

\section{Proof of Proposition 1:}

The existence of the symmetric equilibrium has already been shown in the main text. To see that there can be no asymmetric equilibrium, suppose w.o.l.g. that $e_{i}>e_{j}$ which implies

$$
\begin{aligned}
\frac{\beta-\nu^{\prime}\left(2 e_{i}-2 e_{j}\right)}{c} & >\frac{\beta-\nu^{\prime}\left(2 e_{j}-2 e_{i}\right)}{c} \Leftrightarrow \\
\nu^{\prime}\left(2 e_{i}-2 e_{j}\right) & <\nu^{\prime}\left(2 e_{j}-2 e_{i}\right) \Leftrightarrow \\
d \cdot\left(2 e_{i}-2 e_{j}\right) & <a \cdot\left(2 e_{j}-2 e_{i}\right) \Leftrightarrow \\
d & <-a
\end{aligned}
$$

which yields a contradiction.

\section{Proof of Proposition 2:}

From solving the system of equations (3) and (4) for $e_{i 2}$ and $e_{j 2}$ the second period equilibrium effort levels are

$$
\begin{aligned}
& e_{i 2}=\frac{\beta}{c}-\frac{d}{(c+a+d)}\left(e_{i 1}-e_{j 1}\right), \\
& e_{j 2}=\frac{\beta}{c}+\frac{a}{c+a+d}\left(e_{i 1}-e_{j 1}\right) .
\end{aligned}
$$

The total second period effort exerted is

$$
e_{i 2}+e_{j 2}=\frac{2 \beta}{c}-\left(\frac{d-a}{c+a+d}\right)\left(e_{i 1}-e_{j 1}\right)
$$

which is strictly decreasing in $e_{i 1}-e_{j 1}$ when $d>a$.

\section{Proof of Proposition 3:}


The existence of the symmetric equilibria follows directly from the text. We show by contradiction that there are no asymmetric equilibria. Suppose that there is an asymmetric equilibrium, i.e. $e_{i 1}>e_{j 1}$. Necessary and sufficient conditions for the existence would be that

$$
\begin{aligned}
& \beta\left(\frac{c+2 a+d}{(c+a+d)}\right)-\frac{(c+d) d c}{(c+a+d)^{2}}\left(e_{i 1}-e_{j 1}\right)-c e_{i 1}=0 \\
& \beta\left(\frac{c+2 d+a}{(c+a+d)}\right)+\frac{(c+a) a c}{(c+a+d)^{2}}\left(e_{i 1}-e_{j 1}\right)-c e_{j 1}=0
\end{aligned}
$$

But then $e_{i 1}>e_{j 1}$ is equivalent to

$$
\begin{gathered}
\beta \frac{c+2 a+d}{c+a+d}-\frac{(c+d) d c}{(c+a+d)^{2}}\left(e_{i 1}-e_{j 1}\right)>\beta \frac{c+2 d+a}{c+a+d}+\frac{(c+a) a c}{(c+a+d)^{2}}\left(e_{i 1}-e_{j 1}\right) \Leftrightarrow \\
\beta\left(\frac{c+2 a+d}{c+a+d}-\frac{c+2 d+a}{c+a+d}\right)>\left(\frac{(c+d) d c}{(c+a+d)^{2}}+\frac{(c+a) a c}{(c+a+d)^{2}}\right)\left(e_{i 1}-e_{j 1}\right) \Leftrightarrow \\
\underbrace{\beta \frac{a-d}{c+a+d}}_{<0}>\underbrace{\frac{c d+d^{2}+c a+a^{2}}{(c+a+d)^{2}} c\left(e_{i 1}-e_{j 1}\right)}_{>0}
\end{gathered}
$$

which yields a contradiction.

To see that utility levels are higher in the transparent setting note that in any symmetric equilibrium in which both agents choose an effort level $e$ an agent's first period utility is equal to

$$
\alpha+\beta(2 e)-\frac{c}{2} e^{2}
$$

This function is strictly increasing in $e$ as long as $e<\frac{2 \beta}{c}$. As

$$
\frac{\beta}{c} \leq \frac{\beta}{c}\left(\frac{c+2 a+d}{c+a+d}\right)<\frac{\beta}{c}\left(\frac{c+a+2 d}{c+a+d}\right)<\frac{2 \beta}{c}
$$

in any equilibrium the agents will have a higher utility than in the nontransparent case. 


\begin{tabular}{lccc}
\hline \hline & $(1)$ & $(2)$ & $(3)$ \\
& $\begin{array}{c}\text { Score } \\
\text { change }\end{array}$ & $\begin{array}{c}\text { Blocks } \\
\text { change }\end{array}$ & $\begin{array}{c}\text { Time outs } \\
\text { change }\end{array}$ \\
\hline Team Difference & $-0.969^{* * *}$ & $-1.069^{* * *}$ & $1.018^{* * *}$ \\
in all previous periods & $(0.11)$ & $(0.15)$ & $(0.12)$ \\
Constant & $-2.739^{* * *}$ & $-2.852^{* * *}$ & $3.068^{* * *}$ \\
& $(0.41)$ & $(0.55)$ & $(0.44)$ \\
\hline Observations & 352 & 352 & 352 \\
Number of subjects & 88 & 88 & 88 \\
$R^{2}$ & 0.30 & 0.21 & 0.26 \\
\hline \hline Standard errors in parentheses, ${ }^{* * *} \mathrm{p}<0.01,{ }^{* *} \mathrm{p}<0.05,{ }^{*} \mathrm{p}<0.1$
\end{tabular}

Fixed effects estimation (period dummies included)

Table A1: The impact of the mean difference in past aggregate efforts 


\begin{tabular}{|c|c|c|c|}
\hline & $\begin{array}{c}(1) \\
\text { Score } \\
\text { change }\end{array}$ & $\begin{array}{c}(2) \\
\text { Blocks } \\
\text { change }\end{array}$ & $\begin{array}{c}(3) \\
\text { Time outs } \\
\text { change }\end{array}$ \\
\hline $\begin{array}{l}\text { Team Difference } \\
\text { in the previous period }\end{array}$ & $\begin{array}{c}-0.301^{* * *} \\
(0.037)\end{array}$ & $\begin{array}{c}-0.358^{* * *} \\
(0.051)\end{array}$ & $\begin{array}{c}0.290^{* * *} \\
(0.042)\end{array}$ \\
\hline Score in period 1 & $\begin{array}{l}-0.127^{*} \\
(0.076)\end{array}$ & $\begin{array}{c}-0.218^{* *} \\
(0.10)\end{array}$ & $\begin{array}{c}0.130 \\
(0.086)\end{array}$ \\
\hline Score in period 7 & $\begin{array}{l}0.139^{* *} \\
(0.054)\end{array}$ & $\begin{array}{c}0.209^{* * *} \\
(0.074)\end{array}$ & $\begin{array}{c}-0.156^{* *} \\
(0.061)\end{array}$ \\
\hline Constant & $\begin{array}{c}-3.536^{* * *} \\
(0.88)\end{array}$ & $\begin{array}{c}-3.009^{* *} \\
(1.20)\end{array}$ & $\begin{array}{c}3.803^{* * *} \\
(0.99)\end{array}$ \\
\hline Observations & 352 & 352 & 352 \\
\hline Number of Subjects & 88 & 88 & 88 \\
\hline 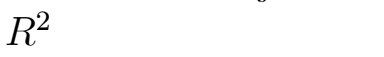 & . & . & . \\
\hline
\end{tabular}

Table A2: The impact of the mean difference in aggregate past efforts controlling for individual abilities

\begin{tabular}{cc}
\hline \hline Periods & Transparent vs. Intransparent Condition \\
\hline 2 & $3.467^{* * *}$ \\
3 & $3.360^{* * *}$ \\
4 & $3.075^{* * *}$ \\
5 & $2.259^{* *}$ \\
6 & 0.965 not significant \\
\hline \hline${ }^{* * *} p<0.01,{ }^{* *} p<0.05,{ }^{*} p<0.1$
\end{tabular}

Absolute value of $\mathrm{z}$-statistics

Table A3: Mann-Whitney-U test: z-values regarding differences between transparent and non transparent condition 


\section{Instructions (non-transparent condition)}

Welcome to this experiment:

Please read these instructions carefully:

- All decisions you make in this experiment are anonymous

- At the end of the experiment you will also be paid out anonymously

- During the experiment no communication is allowed

\section{Procedure:}

This experiment consists of 7 periods, each of which lasts for 8 minutes. Periods 1 and 7 differ from periods 2 to 6

Periods 1 and 7 are played as follows:

You are requested to count the number of the "Sevens" (the digit 7) in a block of random numbers. You enter this number in the corresponding box and confirm your choice with OK

\section{Payoff for the period 1 and period 7:}

For each correct answer you receive 14 Cent

ATTENTION: For each wrong answer 1 Cent will automatically be deducted from your individual account

\section{Periods 2 to 6 of this experiment are played as follows:}

You will be randomly assigned to another participant where the two of you form a team. This assignment is the same for the whole experiment. That is, you play with the same partner from period 2 to period 6 . However, you and your partner remain anonymous.

\section{In periods 2 to 6 you can choose between two options:}

1. You can work on the block of random numbers and count the numbers of the „Sevens" in this block (analogously to round 1 and 7) 
OR

2. You can take a time out by pressing the "time out" button. If you press the "time out" button the counting task is blocked and you cannot continue working on any block of random numbers for 25 seconds.

\section{Payoff for the periods 2 to period 6:}

1. For each correct answer in the counting task, 14 Cents will be paid into your team account. For each correct answer of your team partner 14 Cent will also be paid into your the team account.

The team account will be equally divided between you and your partner at the end of each period.

ATTENTION: For each wrong answer 1 Cent will automatically be deducted from your individual account

2. Each time you press the "time out" button 10 Cent will be paid into your individual account.

After each period you will see a table on the screen displaying the following information:

1. The number of blocks you finished in the previous period

2. The number of correct answers you gave in the previous period

3. The number of time outs you took in the previous period

The table with the details for the particular period looks as follows:

Screenshot

Your partner receives the same information about his own performance. Neither you nor your partner learn about the number of correct answers the other team member gave in the respective round. After the last period (period 7) 
you will be informed about your total payoff. In addition to that you receive a show up fee of $2.50 €$. Please stay at your seat until we call on your cabin number. Please bring along these instructions and your cabin number. Thank you for your participation! 


\section{References}

Admati, M., A.R.and Perry (1991): Joint projects without commitment. Review of Economic Studies, 58, pp. 259-276.

Alchian, A. and Demsetz, H. (1972): Production, Information Costs, and Economic Organization. American Economic Review, 62, pp. 777-795.

Backes-Gellner, U., Mohnen, A. and Werner, A. (2006): Team Size and Effort in Start-Up-Teams - Another Consequence of Free-Riding and Peer Pressure in Partnerships. Working Paper, University of Cologne and University of Zurich.

Barron, J. M. and Gjerde, K. P. (1997): Peer Pressure in an Agency Relationship. Journal of Labour Economics, 15, pp. 234-254.

Biel, P. R. (2004): Inequity Aversion and Team Incentives. Working Paper University College London.

Bolton, Gary E. and Ockenfels, Axel (2000): ERC - A Theory of Equity, Reciprocity and Competition. American Economic Review, 90, pp. 166193.

Che, Y.-K. and Yoo, S.-W. (2001): Optimal Incentives for Teams. American Economic Review, 91, pp. 525-54.

Demougin, D. and Fluet, C. (2003): Inequality Aversion in Tournaments. Discussion Paper Humbold University Berlin.

Englmaier, F. (2004): A Survey on Moral Hazard, Contracts, and Social Preferences. In: Agarwal, B. and Vercelli, A. (Ed.) Psychology, Rationality and Economic Behavior: Challanging standard assumptions (forthcoming).

Englmaier, F. and Wambach, A. (2002): Contracts and Inequity Aversion. CESifo Working Paper 809, Universität München. 
Falk, A. and Ichino, A. (2006): Clean Evidence on Peer Pressure. Journal of Labor Economics, 24, p. 39Ü57.

Fehr, Ernst and Schmidt, Klaus M. (1999): A Theory of Fairness, Competition, and Cooperation. Quarterly Journal of Economics, 114, pp. 817-868.

Fershtman, C. and Nitzan, S. (1991): Dynamic voluntary provision of public goods. European Economic Review, 35, pp. 1057-1067.

Fischbacher, U. (1999): z-Tree - Zurich Toolbox for Readymade Economic Experiments - Experimenter's Manual. Working Paper No. 21, Institute for Empirical Research in Economics, University of Zurich., working Paper Nr. 21, Institute for Empirical Research in Economics, University of Zurich.

Greiner, B. (2003): An Online Recruitment System for Economic Experiments. In: Kremer, K. and Macho, V. (Ed.) Forschung und wissenschaftliches Rechnen, GWDG Bericht 63, Göttingen: Gesellschaft für Wissenschaftliche Datenverarbeitung, pp. 79-93.

Grund, C. and Sliwka, D. (2005): Envy and Compassion in Tournaments. Journal of Economics and Management Strategy, 14, pp. 187-207.

Holmström, B. (1982): Moral Hazard in Teams. Bell Journal of Economics, 13, pp. 324-340.

Huck, S. and Biel, P. R. (2006): Endogenous leadership in teams. Journal of Institutional and Theoretical Economics (forthcoming).

Ichino, Andrea and Maggi, Giovanni (2000): Work Environment and Individual Background: Explaining Regional Shirking Differentials in a Large Italian Firm. Quarterly Journal of Economics, 115, pp. 1057-1090.

Itoh, H. (2004): Moral Hazard and Other-Regarding Preferences. Japanese Economic Review (forthcoming). 
Kandel, Eugene and Lazear, Edward P. (1992): Peer Pressure and Partnerships. Journal of Political Economy, 100, pp. 801-17.

Knez, M. and Simester, D. (2001): Firm-Wide Incentives and Mutual Monitoring at Continental Airlines. Journal of Labor Economics, 19, pp. 743772 .

Marx, L. M. and Matthews, S. A. (2000): Dynamic Voluntary Contribution to a Public Project. Review of Economic Studies, 67, pp. 327-358.

Masclet, D. (2002): Peer Pressure in Work Teams: The Effects of Inequity Aversion. Working Paper, University of Lyon.

Newhouse, J.P. (1973): The Economics of Group Practice. Journal of Human Resources, 8, pp. 37-56.

Prendergast, Canice J. (1999): The Provision of Incentives in Firms. Journal of Economic Literature, 37, pp. 7-63.

Sausgruber, R. (2005): Testing for Team Spirit - An Experimental Study. Working Paper, University of Innsbruck. 